\title{
Paradoja de la minería y pobreza en el Perú
}

\author{
Lida Violeta Asencios Trujillo \\ Universidad Nacional de Educación Enrique Guzmán y Valle
}

\section{Resumen}

\begin{abstract}
e hace una revisión y análisis de la minería en el Perú su importancia en el crecimiento económico, la generación de trabajo y cómo esto contribuye con la reducción o el incremento de la pobreza. Se describen los porcentajes de exportación e importe del sector minero en el país y se analiza en función a la pobreza que existe en cada departamento. Específicamente, se hace referencia a factores que de una u otra manera posibilitan el mejoramiento de las condiciones de vida del ciudadano haciendo buena inversión y atendiendo a las necesidades de la gente o simplemente si no se implementa, tiene una enorme repercusión en la pobreza de los ciudadanos. Se señalan específicamente algunos departamentos del país donde existe mayor explotación minera, pero también mayor crecimiento de pobreza, evidenciando la paradoja que existe en estos dos fenómenos.
\end{abstract}

\section{Palabras clave:}

Minería, pobreza, exploración, exportación.

\section{Introducción}

I

a minería es una actividad primordial para el crecimiento económico de cualquier país. En este sector el Perú ha logrado un posicionamiento privilegiado a nivel mundial al ubicarse entre los primeros productores mundiales de oro, plata y cobre, y otros metales. Además esta actividad es uno de los motores de la economía y sus envíos representan alrededor del $60 \%$ de las exportaciones. Por ejemplo, las exportaciones solo de oro durante el 2015, alcanzaron los US $\$ 6.590$ millones y representaron el 19\% del total de los despachos al exterior y el $35 \%$ de los envíos mineros, que cerraron el año en US $\$ 18,832$ millones. En este año, la cifra hasta febrero estuvo por encima del $1.13 \%$ del mismo mes del año pasado y de la expansión de un 3.41\% registrada en enero. En general se espera que para este año el sector minero crezca 7,7\%, con tendencia a mejorar en el 2017. 
Sin embargo, así como la minería ha sido el impulsor de un crecimiento económico en el país, también, según el informe de Instituto Nacional de Estadística e Informática (INEI) ha disminuido la pobreza a nivel nacional, decir, habría una correlación entre esta actividad de la minería y la reducción de la pobreza. Pero ¿qué pasa en algunos departamentos como Cajamarca, La Libertad, que la situación de pobreza ha empeorado? En estos lugares, ¿Esta actividad no ha resultado beneficiosa para impulsar el desarrollo económico en las familias?

Según el mapa de pobreza del Instituto Nacional de Estadística e Informática (INEI), (2015), Cajamarca presenta una pobreza extrema en el intervalo de 16.6\% a 23.9\%; en tanto que más del 50\% de la población son pobres. Luego esta Amazonas, Ayacucho, Huancavelica, Apurímac, Huánuco, La Libertad, Loreto, Pasco, Piura, Puno, San Martín, también aparecen, Ancash, Cusco, Junín, Lambayeque y Ucayali y finalmente Arequipa, Ica, Madre de Dios, Moquegua, Provincia Constitucional del Callao, Provincia Lima, Región Lima, Tacna y Tumbes.

Como se observa, no existe coherencia entre el crecimiento económico basado en la minería, en algunos lugares del país y la reducción de pobreza, por el contrario existe un aumento de pobreza justamente en los departamentos donde posiblemente hay mayor actividad minera.

\section{Minería y pobreza}

Según el Ministerio de Energía y Minas (2015), la utilización de la producción minera en el Perú presenta una clara tendencia hacia el mercado externo, debido a que más del 95\% de la producción es exportada. Esto se debe a:

i) La elevada demanda externa de grandes volúmenes de concentrado y metales.

ii) Los contratos de comercialización firmados con anticipación entre las empresas mineras y clientes extranjeros, dada la determinación de los precios en el mercado internacional por ser commodities, reduciendo la posibilidad de ofrecer la producción en el mercado nacional.

iii) Los beneficios de la exportación en materia fiscal (cero aranceles) como parte de las políticas de desarrollo del comercio internacional. 
iv) A que el mercado interno se surte de minerales importados provenientes, en su mayoría de países vecinos sudamericanos ya que cuenta con una menor demanda en comparación con el mercado internacional.

Se debe principalmente a estas características de políticas de desarrollo del comercio internacional que la inversión minera en nuestro país continúa creciendo. Bessombes (2016) revela que en enero de este año las inversiones mineras superaron los US\$ 351 millones, destinados mayoritariamente a obras de infraestructura, actividades de explotación y equipamiento.

Actualmente, se continúa haciendo exploración en distintos puntos de distintos departamentos y desde el exterior posiblemente a pesar de los conflictos sociales que estos generan se sigue viendo al Perú como un país atractivo para realizar inversiones. A nivel mundial, según el índice de los países más atractivos para la inversión minera, el Perú cayó 10 casillas, sin embargo, sigue ocupando el segundo lugar en América Latina detrás de Chile y desplazando a México (37) en dicha posición. Desde la medición de 2014, el país pasó del puesto 26 al 36 en el ranking de un total de 109 países analizadas a nivel global. Luego siguen Colombia (en el puesto 55), Brasil (56), Nicaragua (65), Salta en Argentina (71), Panamá (74), San Juan en Argentina (75) y República Dominicana (81). A nivel mundial, Australia, Canadá y Estados Unidos concentran las mejores zonas para la inversión en este sector. También asoman Irlanda y Finlandia, mientras que Australia Occidental ocupó el primer puesto y desplazó a Nevada (Fraser Institute Annual, 2015).

La Sociedad Nacional de Minería, Petróleo y Energía en el 2011 ya comentaba que los descensos en el ranking mundial del Perú en esta materia, muestra que la percepción se está deteriorando tanto en términos absolutos como relativos. A nivel desagregado, los mayores retrocesos en las percepciones sobre el Perú se dieron en las políticas relacionadas con la regulación laboral y ambiental. Sin embargo, se observa una mejora en las percepciones de la calidad en infraestructura y una menor incertidumbre de protección de áreas y reservas nacionales.

Por lo que se sabe, según el reporte del Instituto Fraser, para tener claro esta comparación entre los países, se mide entre otras cosas el aspecto geológico, las 
buenas prácticas en minería y aspectos adicionales considerando la percepción de algunas empresas mineras. Estos aspectos es lo que posiciona al Perú en el puesto 36. Y el aspecto por lo que bajo 10 posiciones básicamente sería por temas asociados a conflictividad minera, conflictos sociales y temas relacionado que enturbian un poco el nivel competitivo del país.

Morón (2007) ha señalado que la competitividad del sector minero es importante debido a que permite desarrollar el sistema productivo necesario para captar las oportunidades que se presentan, en la actualidad de alta demanda de commodities. Y los elementos que están dentro de esta característica competitiva en la minería en el Perú son:

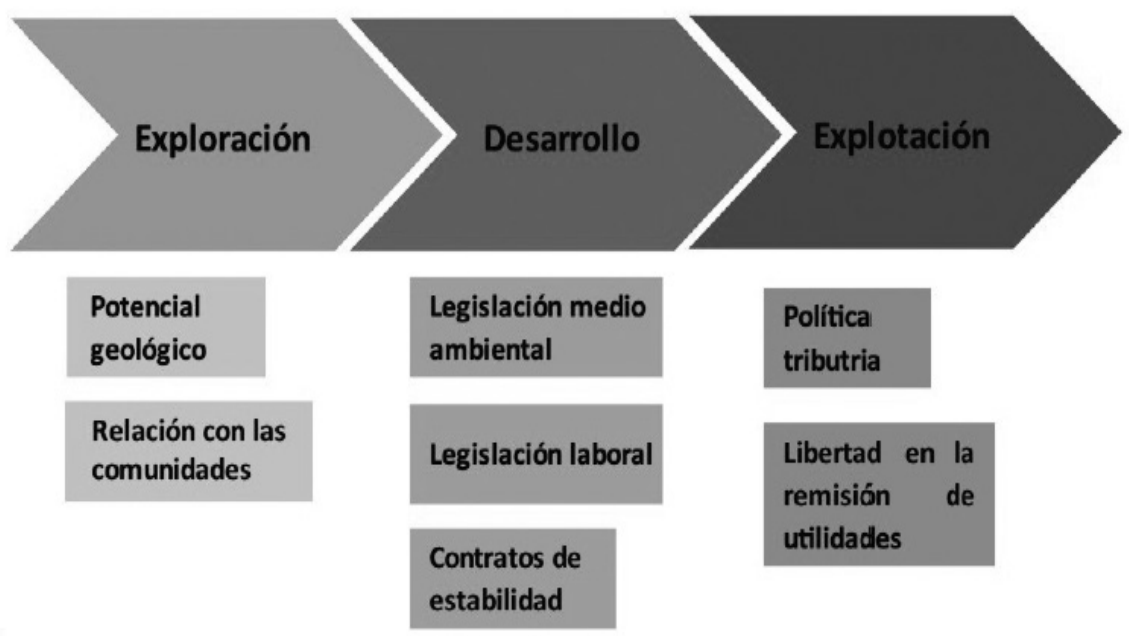

Fuente: elementos de competitividad (Moron, 2007). 
Si bien es cierto que el crecimiento económico del país viene principalmente de la minería, también hay que notar, en relación con la pobreza. A nivel de estado, existe un desafío por resolver. Según Daly (2015) la pobreza se ha reducido en el país en 10 puntos porcentuales desde el 2009. Los cambios positivos han sido aún mayores en el área rural, donde la pobreza se redujo en un $20 \%$. Estos se deberían a que durante los últimos años el país ha crecido económicamente. Es decir, lo que ha sacado realmente a la gente de la pobreza es el crecimiento económico, el aumento del PBI. Esto a la vez, (crecimiento del $\mathrm{PBI}$ ) se debería principalmente a la minería. Dado que según Aníbal Sánchez, jefe del INEI, los lugares en donde se redujeron más la pobreza son los que tienen un asentamiento minero o acceso al canon. Sin embargo, el canon por sí solo no explica toda la reducción de la pobreza. Otro factor sería, el incremento del gasto público, como la construcción de carreteras u obras de agua y saneamiento (Daly, 2015).

Otro factor que reduce la pobreza, son las inversiones en los programas sociales (INEI, 2015). Para el ministro de Economía y Finanzas, Alonso Segura, un $87 \%$ de la reducción de la pobreza entre el 2013 y 2014 se explica por los programas sociales y solo $13 \%$ se debería al crecimiento de la economía del país. Tal vez, este es el factor más coherente a la explicación de la reducción de la pobreza, pues, por el otro, si analizamos con mayor detenimiento las zonas donde hay mayor cantidad de minas también se perciben mayor pobreza.

Según el documento de Desnutrición crónica infantil cero en 2016, las regiones que tienen mayor porcentaje de minas, también, encabezan el ranking de desnutrición crónica infantil en el Perú, siendo las regiones como: Huancavelica (46,4\%), Cajamarca (29,9\%), Huánuco (28,8\%), Apurímac (31,3 \%) y Ayacucho (28,1 \%) (SERVINDI, 2015).

Si analizamos esta situación, Huancavelica tiene casi el 50\% de su territorio concesionado a la minería (40.34\%); Cajamarca con el 44.37\%; Ancash, el $36.1 \%$ de su espacio geográfico está concesionado; Apurímac tiene el 54.44\% 
de su territorio concesionado y en Ayacucho el porcentaje del territorio concesionado alcanza el 26.2\%. En cada uno de estos departamentos con cerca del 50\% de sus territorios concesionados al sector minero, existe más de $3 / 4$ partes de población en situación de pobreza. La población tiene principalmente, escaso acceso a los servicios básicos, educación, salud, vivienda, entre otros.

Según el INEI, existen otros factores a parte de la minería o el acceso al canon, por los cuales la población no sale de la pobreza. Uno de ellos es la mala inversión: Si analizamos la situación de los distritos más pobres, vemos que dos tercios redujeron su capacidad de gasto del presupuesto. Solo por resaltar un caso, el de Bambamarca, en La Libertad, su presupuesto para proyectos de inversión pública disminuyo en 62,5 puntos porcentuales, mientras que la pobreza aumentó en aproximadamente 30 puntos (Daly, 2015). Otro de los factores de la pobreza es la inoperancia de las mismas instituciones. Los políticos, quienes son los encargados de implementar las políticas públicas y los encargados de realizar obras, proyectos de inversión importantes, entre otras actividades, simplemente gastan el dinero en cosas que no sirven. No toman medidas para aprovechar la inversión y el comercio.

Por ello, para una mejor distribución de los recursos, el Estado también tiene que distribuir mejor los recursos, controlar o evaluar el gasto que se hacen. También, promover la inversión privada porque es su obligación con el pueblo, a través del financiamiento de obras de electrificación rural, saneamiento y una serie de actividades en diferentes sectores.

\section{Conclusión}

Hacer una análisis tanto la actividad minera como de la disminución o el aumento de la pobreza en el Perú, es muy complejo. Existen diferentes factores por lo que ambas actividades se relaciona, ya sea por el canon, las regalías, etc. o también por la mala explotación que hacen, perjudicando el medio ambiente y la salud de las personas que habitan en esos lugares. Ahora queda 
enfrentar este gran reto para cambiar la percepción negativa de la minería, así como solucionar los conflictos sociales a través de procesos de diálogo pacíficos sin llegar a la violencia. Este desafío requiere la participación de varias instituciones del Estado, las empresas y la población en general.

\section{Referencias}

Ministerio de Energía y Minas (2015). Anuario minero. Recuperado de http://www.minem.gob.pe/minem/archivos/file/Mineria/PUBLICACIONES/ANUARIOS/2015/03\%20PRODUCCION.pdf.

Instituto Nacional de Estadística e Informática (INEI) (2015). Perú síntesis estadística 2015. Recuperado de https://www.inei.gob.pe/media/MenuRecursivo/publicaciones_digitales/Est/Lib1292/libro.pdf.

Bessombes, C. (2016, marzo 04). Los inversionistas en exploración minera aún ven atractivo al Perú. La Republica, p.13.

Fraser Institute Annual (2015). Survey of Mining Companies. Recuperado de https://www.fraserinstitute.org/sites/default/files/survey-of-mining-companies-2015.pdf.

Sociedad Nacional de Minería, Petróleo y Energía (2011). La tributación minera en el Perú. Recuperado de http://www2.congreso.gob.pe/ sicr/cendocbib/con3_uibd.nsf/059028AB8F0A61EE0525785D0059D$\mathrm{BE} 1 /$ FILE/la-tributacion-minera-en-el-peru-contribucion-carga-y-fundamentos-conceptuales.pdf.

Moron, E. (2007). Competitividad del Sector Minero. Recuperado de http:// www.iimp.org.pe/website2/publicaciones/EstudioIIMP4_Competitividad.pdf. 
Teoría

Daly, G. (2015). Los más pobres del Perú: un mapa con altibajos [INFOR$\mathrm{ME}$. Recuperado de http://elcomercio.pe/peru/pais/mas-pobres-peru-mapa-altibajos-noticia-1845769

SERVINDI (2015). Desnutrición crónica infantil cero en 2016. Recuperado de http://www.servindi.org/actualidad/76239 